\title{
Reseña teórica de la inteligencia emocional: modelos e instrumentos de medición ${ }^{1}$
}

\author{
Theoretical review of emotional intelligence: \\ models and measuring instruments \\ Revisão teórica sobre inteligência emocional: mo- \\ delose instrumentos de medição
}

Recibido: octubre de 2012

Aceptado: diciembre de 2012

Jhony Jalier Mejía Díaz

\section{Resumen}

La presente revisión teórica de la inteligencia emocional (IE) inicia con las conceptualizaciones realizadas por Galton, Binet, Stemberg Thurstone, Thordinke, Gardner, quienes en su momento histórico lograron cimentar las bases para el nacimiento de la inteligencia emocional como un constructo teórico introducido por primera vez en la literatura científica en los años noventa. Desde entonces se han desarrollado diferentes modelos de IE y al mismo tiempo se han incrementado las contribuciones investigativas. En el artículo se procede a describir en detalle los modelos de IE más representativos, como: 1) el modelo de habilidad mental (Ability Based) desarrollado por Mayer y Salovey; 2) el modelo de las competencias emocionales de Goleman; 3) el modelo de inteligencia emocional social de Bar-On. Seguidamente se describen los estudios experimentales más representativos y los instrumentos de medición de la IE, basados en los modelos mencionados anteriormente, y, como consideración final del autor, algunos estudios realizados en inmigrantes en Europa.

Palabras clave: inteligencia emocional, modelos de inteligencia emocional, medición de la inteligencia emocional.

\begin{abstract}
This theoretical review of emotional intelligence (EI) starts from the earliest conceptualizations made by Galton, Binet, Stemberg Thurstone and Thordinke Gardner, who, during their historical period, were successful in laying the basis for the birth of emotional intelligence as a theoretical construction which was introduced for the first time, in scientific literature, in 90's. Since then, different EI models have been developed and investigative contributions have been increased. In this article, the most representative EI models will be described with details, such as: 1) Mental ability model (Ability Based) developed by Mayer and Salovey 2) Model of emotional competences by Goleman 3) Model of emotional social intelligence of Bar-On. The measuring instruments of EI will be described, based on the models mentioned before, as well the most representative
\end{abstract}

1 Artículo de Revisión.

2 Doctorado en Psicología e Investigación, Universitá degli Studi di Palermo, Italia. Contacto: jhonyjalier.mejiadia@unipa.it, jhonnyjaliermejiad@gmail.com 
experimental researches of EI and, as a final observation of the author, some researches based on immigrants in Europe.Keywords: childhoods, subjectivities, subjectivity, cyberculture, uses, appropriations, creation.

Keywords: emotional intelligence, models of emotional intelligence, measurement of emotional intelligence.

\section{Resumo}

A presente revisão teórica da inteligência emocional (IE) começa com os conceitos feitos por Galton, Binet, Stemberg, Thurstone, Thordinke, Gardner, os quais, em seu momento histórico, conseguirão estabelecer as bases para o surgimento da inteligência emocional como uma construção teórica, que foi introduzido pela primeira vezna literatura científica na decada dos 90. Desde então, temos visto ó desenvolvimento de diferentes modelos de IE, e ao mesmo tempo aumentaram as contribuições da pesquisa. $\mathrm{O}$ artigo pretende descrever detalhadamente os modelos mais representativos da IE como: 1) O modelo da capacidade mental (Ability base), desenvolvido por Mayere Salovey, 2) O modelo de Goleman das competências emocionais, 3). O modelo de inteligência emocional social de Bar-On. En seguida si descreve os estudos experimentais mais representativos e os instrumentos de medição da IE baseados nos modelos acima referidos; como última consideração do autor alguns estudos sobre imigrantes na Europa.

Palavras-chave: inteligência emocional, modelos de inteligência emocional, a medição da inteligência emocional.

\section{La inteligencia emocional}

La aparición del concepto de inteligencia emocional (IE), en la década de los noventa, inicia a partir del artículo publicado por Peter Salovey y John Mayer, Imagination, Cognition and Personality (Salovey \& Mayer, 1990); esta ha cobrado gran popularidad en sectores como el científico internacional y el de la comunidad en general. Dicha expansión se debe en parte al éxito que tuvo el best seller Emotional Intelligence, escrito por el psicólogo y periodista Daniel Goleman en 1995. En el interior de esta resuena con gran fuerza la necesidad del estudio de la inteligencia humana, donde no solamente prevalece el estudio de los aspectos cognitivos e intelectuales, sino que señala la importancia adecuada en el uso y gestión del mundo emocional y social a fin de comprender el rumbo de la vida de las personas.

Antes de iniciar con la descripción de los modelos de la IE, se hace necesaria una breve revisión histórica del concepto de inteligencia y sus principales representantes, para proseguir con el objetivo de este artículo.

\section{Raíces históricas de la inteligencia emocional}

La inteligencia ha sido uno de los temas más frecuentemente afrontados por los psicólogos. El estudio de la inteligencia constituye un sector de investigación que nace al mismo tiempo que la psicología experimental.

Uno de los principales objetivos que impulsaron originariamente la investigación en esta área es la necesidad de medir las diferencias individuales en las habilidades intelectuales, y cómo estas son utilizadas en diversos ámbitos, con intereses de tipo diagnóstico o heurístico.

En las siguientes líneas se evidenciarán los modelos más representativos acerca de la inteligencia: 
En Inglaterra, Francis Galton (1885) concebía la inteligencia como una habilidad general que forma parte de todo tipo de actividad cognitiva, en mayor o en menor proporción, que difiere de una persona a otra y, por tanto, determina el nivel general de inteligencia de cada sujeto. Galton es considerado el fundador de la psicología diferencial, pues ha explorado la inteligencia esencialmente en la dimensión sensorial relativa a peso, vista, altura, audición, capacidad respiratoria, tiempo de respuesta, "reacción", etc. Estas dimensiones sensoriales eran utilizadas para la evaluación de la inteligencia de un individuo. Además, se le reconoce como un pionero en la aplicación de las escalas de valoración y de cuestionarios, al igual que en la elaboración del método estadístico, para el análisis de las diferencias individuales.

De sus investigaciones, Galton obtiene una escala de siete intervalos de clasificación para el ser humano según sus capacidades: A, apenas superior a la media, a G; genio; al igual que otros investigadores de la inteligencia, Galton comparte la aseveración de que el intelecto puede ser medido, sometiendo a los sujetos a pruebas, con las cuales se pueden explorar las capacidades y el conocimiento. El rendimiento obtenido en las pruebas define el nivel intelectual del individuo.

Seguidamente, en Francia, Alfred Binet, a inicios de la década de 1900, define la inteligencia como la habilidad para tomar y mantener determinada dirección, como adaptabilidad a nuevas situaciones y habilidad para criticar los propios actos. En sus trabajos se destaca como uno de los precursores en la medición de la inteligencia; en este sentido, Binet no establece una cantidad, como lo hacen luego Lewis Terman y David Wechsler al presentar el concepto de cociente intelectual (IQ). Desde esta óptica el objetivo de Binet (1905) era el de proveer un número-calidad, a partir de la cual alcanzar un resultado, que pudiese representar el proceso evolutivo y el nivel intelectual alcanzado por un niño. La escala de inteligencia de Binet mide los siguientes dominios en sujetos de 3 a 12 años de edad: 1) la inteligencia pura y simple; 2) las adquisiciones extracurriculares; 3) las adquisiciones relativas al lenguaje y al vocabulario.
La teoría triárquica de la inteligencia, desarrollada por Robert J. Stemberg (1985), el cual es considerado una figura destacada en la investigación de la inteligencia humana. Stemberg define la inteligencia como "actividad mental dirigida con el propósito de adaptación, selección y conformación de entornos del mundo real, relevantes en la vida de uno mismo". La inteligencia sería cuando adecuadamente un sujeto afronta los cambios en su entorno a lo largo de su ciclo de vida. Esta teoría es abarcadora, por lo que la inteligencia no es entendida como habilidad singular, en cambio se deduce como una unidad articulada, compuesta y constituida por partes diversas, puesto que toma en cuenta factores sociales y con-textuales, además de las habilidades humanas, descritas y dispuestas por Stemberg de la siguiente manera:

1) Inteligencia analítica (abstracta): la cual hace referencia al análisis, evaluación y comparación de la información.

2) Inteligencia práctica: se refiere a la capacidad de ejecutar materialmente las cosas aprendidas y procesadas.

3) Inteligencia creativa: está relacionada con las posibilidades de encontrar soluciones originales, producir innovaciones, efectuar un descubrimiento y tener un insight.

El punto de encuentro entre habilidad analítica, práctica y creativa se da con la successfull intelligence, la cual contribuye a desempeñarse de manera eficiente en un determinado contexto sociocultural y, en este mismo orden, lo modifica y selecciona oportunamente el ambiente en función de su propios objetivos. Posteriormente Stemberg hace la inclusión de tres subcategorías: 1) el componente, que toma en consideración el ambiente interno del individuo; 2) el contexto, que hace referencia al ambiente exterior del individuo y que integra la inteligencia social; 3) el componente experiencial, el cual comprende el ambiente interno y externo del sujeto. Stemberg logró destacar el papel de las situaciones concretas, lo cual demuestra el compromiso de no relegar la inteligencia solo a las áreas comunes o tradicionales de la lógica abstracta, con 
lo que reafirma la importancia y pertinencia de un enfoque en el que se le da importancia al contexto.

Por otro lado, el modelo de inteligencia desarrollado por Guilford (1971) amplía considerablemente la naturaleza de la inteligencia al adicionar factores como el juicio social, es decir, la valoración del comportamiento de los otros individuos y la creatividad entendida como pensamiento divergente. La estructura del intelecto de Guilford es extremadamente variada, puesto que incluye un número amplio de habilidades mentales. En su modelo, considera la existencia de 120 factores de base o habilidades primarias; este modelo posteriormente fue ampliado a 150 factores. De esta forma, Guilford considera la estructura del intelecto como el producto de las interacciones de tres procesos de base: 1) operaciones, 2) contenido, 3) producto; con su combinación se constituirían las habilidades. Los tres procesos de base refieren cada uno las siguientes categorías: 1 . Operaciones: valoración, pensamiento convergente, pensamiento divergente, memoria y comprensión; 2 . Contenido: comportamental, semántico, simbólico y figurativo; 3. Producto: unidad, clase, relaciones, sistemas, transformaciones e implicaciones El modelo de la estructura del intelecto de Guilford está representado en el gráfico 1.

El modelo de la inteligencia de L.L. Thurstone (1938) establece el análisis de factores para determinar siete características básicas que parecían conformar la inteligencia: 1)la comprensión verbal (definición y comprensión de palabras); 2) fluidez verbal (ser capaz de pensar palabras rápidamente); 3) numérica (ser capaz de hacer y resolver problemas aritméticos); 4) espacial(ser capaz de comprender relaciones espaciales); 5)memoria mecánica (ser capaz de memorizar y recordar); 6)percepción (ser capaz de captar rápidamente las similitudes, diferencias y detalles de objetos o estímulos); 7) razonamiento(ser capaz de comprender los principios y conceptos para resolver problemas).

El modelo de las inteligencias múltiples de Howard Gardner es la primera teoría que puso en discusión la existencia de un único tipo de

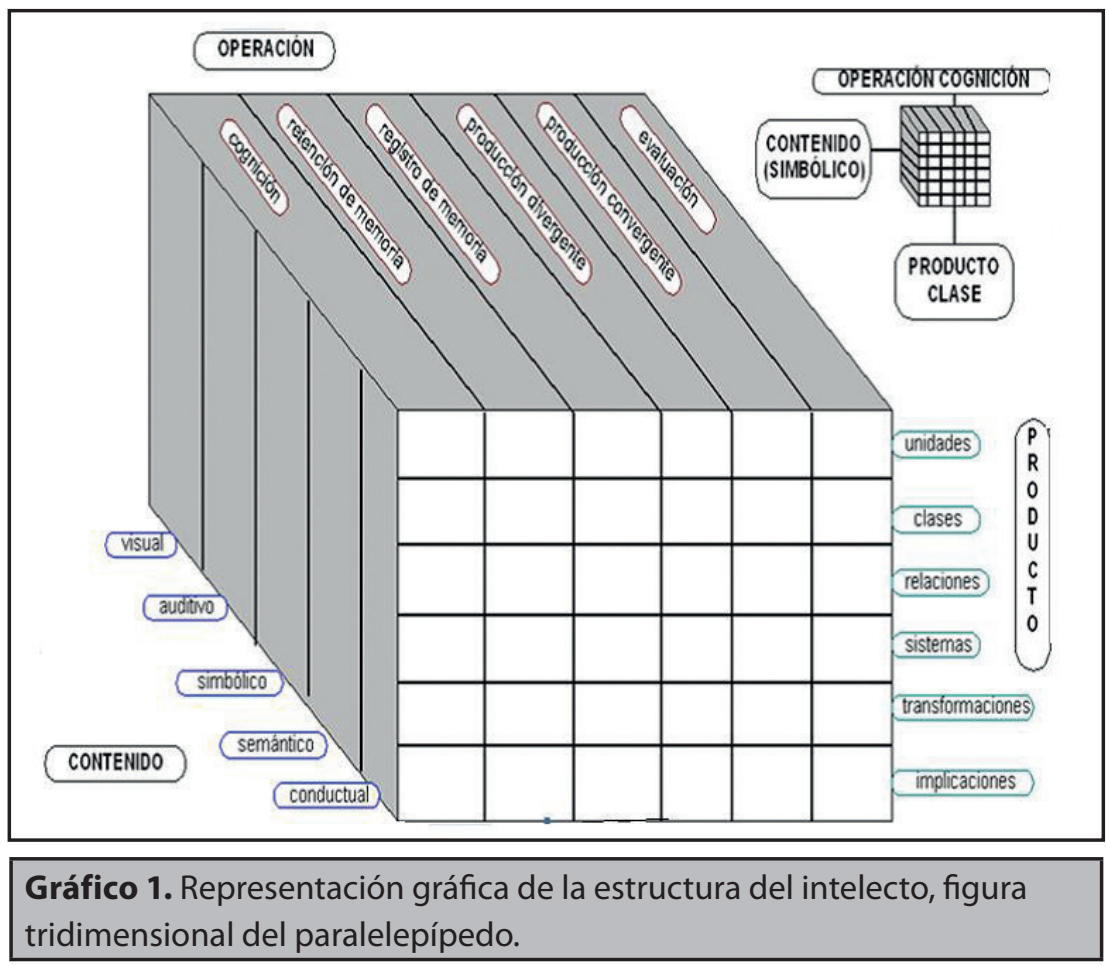

Fuente: elaboración propia. 
inteligencia, y que ha cimentado las bases para desarrollar el concepto de inteligencia emocional; ha sido la teoría de las inteligencias múltiples y la teoría de Stemberg basadas ambas sobre la definición dada por Thordinke acerca de la inteligencia social. Thordinke sostenía la existencia de una inteligencia definida como inteligencia social, la cual es descrita como la habilidad de comprender y relacionarse entre hombres y mujeres, y de actuar de un modo adecuado con las relaciones humanas.

Gardner formula la primera hipótesis sobre la teoría de las inteligencias múltiples en su libro The shattered mind (1993), que posteriormente sería definida en uno de los libros más importantes de Gardner, Frame of mind (1993), en el cual afirma la existencia de siete diferentes tipos de inteligencia, de las cuales un individuo puede hacer uso dependiendo de la situación específica en que se encuentre. A continuación veremos una breve descripción de estas inteligencias:

1) lingüística: permite a los individuos comunicarse con los demás y contribuye al procesamiento de la información lingüística.

2) Espacial: permite al individuo percibir información visual o espacial, lo cual le facilita la transformación y construcción de imágenes sin la necesidad de un estímulo correspondiente.

3) Lógico-matemática: comprende el uso del razonamiento abstracto con relación a las propiedades de base numérica.

4) Musical: es la habilidad que permite al sujeto el crear, comprender y entender composiciones musicales con relación al ritmo.

5) Corpórea o cinestésica: posibilita la utilización del cuerpo con un fin expresivo, controlando los propios movimientos, reconociendo la posición del cuerpo en el espacio. Además, permite la manipulación de objetos con cierto grado de maestría.

6) intrapersonal e interpersonal: facilita la compresión de las propias emociones y las de los demás y contribuye a la regulación de los propios sentimientos
7) naturalista: hace posible distinguir y clasificar aspectos diversos de la realidad física que circunda al individuo, es decir: seres vivos, plantas o animales.

\section{Breve descripción de los modelos teóricos de la inteligencia emocional}

Desde la expansión y el uso del concepto de IE, los teóricos han elaborado un gran número de modelos; se hace necesario aclarar que estos modelos se han basado en tres perspectivas: las habilidades o competencias, los comportamientos y la inteligencia (Neubauer \& Freudenthaler, 2005). Por otro lado, diferentes autores -Bar-On (1997), Cooper \& Sawaf (1997), Shapiro (1997), Goleman (1998) y Gottman (1997), citados por Trujillo \& Rivas (2005) - han publicado y desarrollado otras aproximaciones al concepto de IE, muy diversas; proponen sus propios componentes e instrumentos para la valoración del concepto. De esta misma forma, cada uno de ellos tiene diferencias en las habilidades que debe poseer un individuo emocionalmente inteligente.

A continuación se realizará una descripción de los modelos de IE más representativos, iniciando con los modelos de habilidad mental (ability based models) y prosiguiendo con los modelos mixtos (mixed models).

Los investigadores Salovey y Mayer definieron la IE como "la capacidad para identificar y traducir correctamente los signos y eventos emocionales personales y de los otros, elaborándolos y produciendo procesos de dirección emocional, pensamiento y comportamiento de manera eficaz y adecuada a las metas personales y el ambiente". Dan a entender con esto que el individuo tiene la capacidad para acceder a sus emociones, logrando una sintonización e integración de sus experiencias.

\section{Modelo de IE basado en la habilidad mental (ability based) (Mayer \& Salovey, 1997)}

El modelo de cuatro-ramas de inteligencia emocional o modelo de habilidad (Mayer \& Salovey, 1997) se encuentra dividido en cuatro ámbitos, ordenados principalmente en forma jerárquica: 1) percibir, valorar y expresar emociones con exactitud; 


\begin{tabular}{|c|c|c|c|}
\hline Categoría 1 & Categoría 2 & Categoría 3 & Categoría 4 \\
\hline \multicolumn{4}{|c|}{ La regulación de las emociones para promover el crecimiento emocional e intelectual } \\
\hline $\begin{array}{l}\text { La habilidad para estar } \\
\text { abierto a los sentimientos, } \\
\text { tanto a los placenteros } \\
\text { como a los que no lo son. }\end{array}$ & $\begin{array}{l}\text { La habilidad para emplear } \\
\text { reflexivamente o despren- } \\
\text { derse de una emoción, } \\
\text { dependiendo de su natura- } \\
\text { leza informativa o utilitaria. }\end{array}$ & $\begin{array}{l}\text { La habilidad para moni- } \\
\text { torizar reflexivamente las } \\
\text { emociones personales, así } \\
\text { como el reconocimiento } \\
\text { de cuán claras, influencia- } \\
\text { bles o razonables son. }\end{array}$ & $\begin{array}{l}\text { La habilidad para mane- } \\
\text { jar las emociones en } \\
\text { uno mismo y en otros, } \\
\text { mediante el control de las } \\
\text { emociones negativas y la } \\
\text { focalización en las placen- } \\
\text { teras; tener que reprimir } \\
\text { o exagerar la información } \\
\text { transmitida. }\end{array}$ \\
\hline \multicolumn{4}{|c|}{ Entendimiento y análisis de las emociones; empleo del conocimiento emocional } \\
\hline $\begin{array}{l}\text { La habilidad para describir } \\
\text { las emociones y reconocer } \\
\text { las representaciones de } \\
\text { estas en las palabras. Por } \\
\text { ejemplo, la relación entre } \\
\text { querer y amar. }\end{array}$ & $\begin{array}{l}\text { La habilidad para interpre- } \\
\text { tar los significados de las } \\
\text { emociones con respecto } \\
\text { a las relaciones (por ejem- } \\
\text { plo, la tristeza casi siempre } \\
\text { acompaña a la pérdida). } \\
\end{array}$ & $\begin{array}{l}\text { La habilidad para enten- } \\
\text { der los sentimientos com- } \\
\text { plejos; por ejemplo, la } \\
\text { ambivalencia. }\end{array}$ & $\begin{array}{l}\text { La habilidad para recono- } \\
\text { cer las transiciones entre } \\
\text { las emociones, tales como } \\
\text { la transición de la ira a la } \\
\text { satisfacción o de la ira a la } \\
\text { timidez. }\end{array}$ \\
\hline \multicolumn{4}{|c|}{ Facilitación emocional del pensamiento } \\
\hline $\begin{array}{l}\text { Las emociones dan prio- } \\
\text { ridad al pensamiento, } \\
\text { por medio de dirigir la } \\
\text { atención a la información } \\
\text { importante. }\end{array}$ & $\begin{array}{l}\text { Las emociones están sufi- } \\
\text { cientemente disponibles } \\
\text { como para que puedan } \\
\text { ser generadas como ayuda } \\
\text { para el juicio y la memo- } \\
\text { ria concerniente a los } \\
\text { sentimientos. }\end{array}$ & $\begin{array}{l}\text { El ánimo emocional } \\
\text { modula los cambios en el } \\
\text { individuo: de optimista a } \\
\text { pesimista, lo cual alienta el } \\
\text { reconocimiento de múlti- } \\
\text { ples puntos de vista. }\end{array}$ & $\begin{array}{l}\text { Los estados emocionales } \\
\text { se diferencian y fomen- } \\
\text { tan métodos de solución } \\
\text { de problemas (ejemplo, } \\
\text { la felicidad facilita el razo- } \\
\text { namiento inductivo y la } \\
\text { creatividad). }\end{array}$ \\
\hline \multicolumn{4}{|c|}{ Percepción, evaluación y expresión de la emoción } \\
\hline $\begin{array}{l}\text { La habilidad para identifi- } \\
\text { car la emoción en nuestros } \\
\text { estados físicos, sentimen- } \\
\text { tales y reflexivos. }\end{array}$ & $\begin{array}{l}\text { La habilidad para identifi- } \\
\text { car las emociones en otras } \\
\text { personas, objetos, situacio- } \\
\text { nes, etc., a través del len- } \\
\text { guaje, sonido, apariencia y } \\
\text { comportamiento. }\end{array}$ & $\begin{array}{l}\text { La habilidad para expresar } \\
\text { las emociones con preci- } \\
\text { sión y para expresar las } \\
\text { necesidades de aquellos } \\
\text { sentimientos. }\end{array}$ & $\begin{array}{l}\text { La habilidad para dis- } \\
\text { criminar entre senti- } \\
\text { mientos; por ejemplo, } \\
\text { expresiones honestas ver- } \\
\text { sus deshonestas. }\end{array}$ \\
\hline
\end{tabular}


2) acceder o generar sentimientos que faciliten el pensamiento; 3) comprender emociones y el conocimiento emocional; 4) regular las emociones promoviendo un crecimiento emocional e intelectual (Mayer y Salovey, 1997).

1. Percepción, evaluación y expresión de las emociones: en la primera casilla se hace referencia a la capacidad de percibir las emociones en sí mismos y en los demás. Dicha habilidad es considerada importante debido a que una valoración correcta de las emociones hace que el individuo pueda distinguir entre expresiones emocionales reales o fingidas con relación a la situación vivida. Se trata, entonces, de la precisión con la cual un individuo puede identificar las emociones en un contexto emocional específico (Mayer \& Salovey, 1997). Quien tenga esta habilidad bien desarrollada podrá identificar las expresiones emocionales en los demás, para así modificar y regular su propio comportamiento. Además, el individuo podrá dar respuesta con mayor velocidad con relación a su propio estado emocional y poder expresarlo adecuadamente a los demás (Mayer \& Salovey, 1997).

2. Utilizar las emociones para facilitar el pensamiento: en esta segunda casilla se hace referencia a la capacidad de utilizar las emociones para potenciar y dirigir el pensamiento y para dirigir la creatividad y la resolución de problemas. En otras palabras, se trata de integrar las emociones en los procesos perceptivos y cognitivos. Con esto se quiere indicar que las emociones influencian los procesos cognitivos actuando sobre la resolución de problemas y la toma de decisiones. Esta capacidad se puede entender si se observa cómo esta evoluciona a lo largo del arco de la vida; es decir, un niño llora por la necesidad de alimentarse o la solicitud de protección; las emociones prosiguen su desarrollo logrando con el tiempo direccionar la atención hacia la información de mayor relevancia. De esta misma forma se logra individuar otro aporte de las emociones al pensamiento; según Mayer \& Salovey (1997), la capacidad de generar, sentir, manipular y examinar las emociones, con el fin de entenderlas mejor, lo cual puede ayudar a una persona en la toma de decisiones entre las diferentes posibilidades en el arco de la vida del individuo.

3. Comprender y analizar las emociones. Utilizar el conocimiento emocional: la tercera casilla hace referencia a la capacidad de comprender la combinación de diversas emociones y la transición emocional, es decir, cómo una emoción se puede transformar en otra, y de analizar las emociones en cada uno de sus componentes. Se trata de la capacidad que tiene un individuo de distinguir entre varias emociones, comprender las relaciones que hay entre ellas, de identificación de las consecuencias de las emociones, de comprender las emociones complejas, los estados emocionales contradictorios y la concatenación de las emociones (Mayer \&Salovey, 1997).

4. Regulación reflexiva de las emociones en el promover el crecimiento emocional e intelectual: en la casilla cuatro se hace referencia a la capacidad de gestionar las emociones propias y las de los demás. Se trata de una habilidad muy importante, en cuanto influencia el bienestar del individuo y su capacidad de comportarse adecuada y eficazmente en las situaciones estresantes de la vida cotidiana, moderando las emociones negativas y valorando las positivas, con el objetivo de lograr una buena y adecuada adaptación. A este nivel corresponde la capacidad de tolerar y agrupar las emociones cuando estas son experimentadas, independientemente de la naturaleza de la emoción (agradable o desagradable).

\section{El modelo de las competencias emocionales de Goleman (mixed model)}

El modelo realizado por Goleman logra definir la IE como la capacidad para reconocer y manejar nuestros propios sentimientos, motivarnos y monitorear nuestras relaciones. Afirma que la IE es un factor mucho más determinante que el IQ, debido a que las actitudes emocionales son una metahabilidad que determina cuán bien logramos utilizar nuestras capacidades, incluidas las del intelecto. El modelo de las competencias emocionales (CE) 


\begin{tabular}{|l|}
\hline Tabla 2.Inventario de habilidades emocionales de Goleman. \\
\hline Autoconciencia (self-awareness) \\
\hline - Autoconciencia emocional: reconocimiento de nuestras emociones y sus efectos. \\
- Acertada autoevaluación: conocimiento de nuestras fortalezas y limitaciones. \\
- Autoconfianza: un fuerte sentido de nuestros méritos y capacidades. \\
\hline Autodirección (self-management) \\
\hline - Autocontrol: control de nuestras emociones destructivas e impulsos. \\
- Fiabilidad: muestra de honestidad e integridad. \\
- Conciencia: muestra de responsabilidad y manejo de uno mismo. \\
- Adaptabilidad: flexibilidad en situaciones de cambio u obstáculos. \\
- Logro de orientación: dirección para alcanzar un estándar interno de excelencia. \\
- Iniciativa: prontitud para actuar. \\
\hline Aptitudes sociales (social-awareness) \\
\hline - Influencia: tácticas de influencia interpersonal. \\
- Comunicación: mensajes claros y convincentes. \\
- Manejo de conflicto: resolución de desacuerdos. \\
- Liderazgo: inspiración y dirección de grupos. \\
- Cambio catalizador: iniciación y manejo del cambio. \\
- Construcción de vínculos: creación de relaciones instrumentales. \\
\hline Relaciones de dirección (relationship management) \\
\hline - Trabajo en equipo y colaboración. \\
- Creación de una visión compartida en el trabajo en equipo. \\
- Trabajo con otros hacia las metas compartidas. \\
\hline
\end{tabular}

Fuente: Boyatzis et al. (2000).

(Goleman,1997) comprende una serie de competencias que facilitan a las personas el manejo de las emociones hacia uno mismo y hacia los demás. En un principio este modelo consistía en cinco etapas, las cuales posteriormente fueron modificadas a cuatro grupos (Goleman,1997, 2001) con veinte habilidades cada una: 1) autoconciencia, el conocimiento de nuestras preferencias, sensaciones, estados y recursos internos; 2) autocontrol, manejo de nuestros sentimientos, impulsos, estados y necesidades internas; 3 ) conciencia social, reconocimiento delos sentimientos, preocupaciones y necesidades de otros, y 4) manejo de las relaciones, la habilidad para manejar bien las relaciones y construir redes de soporte (Goleman, 2002).

Revisando los cuatro ámbitos de la IE descritos por Goleman, ha estado fácil para la gran mayoría de los lectores llegar a concluir que se trata de una capacidad fundamental, y, como muchas, existe la posibilidad de desarrollar estas habilidades en cualquier ámbito, como el contexto escolar, laboral, el ámbito de las relaciones familiares y en las relaciones con los pares, a fin de obtener un rendimiento excelente.

\section{Bar-On: modelo de la inteligencia emocional social (mixed model)}

Por su parte, Bar-On ha ofrecido otra definición de la inteligencia emocional tomando como punto de partida a Salovey y Mayer. Describiendo la IE como un conjunto de capacidades no cognitivas, competencias de habilidades aprendidas que influencian la calidad de los individuos para enfrentar eficazmente las demandas y presiones del ambiente ("an array of non cognitive capabilities, competencies, and skills that influence one's ability to succeed in coping with environmental demands and pressures" (Bar-On, 1997, citado por Di Caro y D’Amico, 2008); esta definición es la que representa más controversia debido al uso que el autor 
Tabla 3.Componentes del modelo de inteligencia emocional social de Bar-On.

Componente intrapersonal (intrapersonal component)

- Evalúa la autoidentificación general del individuo, la autoconciencia emocional, la asertividad, la autorrealización e independencia emocional, la autoconciencia (emotional self-awereness), la autoevaluación (self regard).

Componente interpersonal (interpersonal component)

- La empatía, la responsabilidad social, las relaciones sociales.

Componente de manejo de emociones (stress management component)

- La capacidad para tolerar presiones (tolerance stress) y la capacidad de controlar impulsos (impulse control).

Componente de estado de ánimo

- El optimismo (optimism): se refiere a la capacidad de ser optimista y de saber disfrutar de la presencia de otros, además de conservar una actitud positiva ante situaciones adversas. Satisfacción (happiness): se refiere a la capacidad de estar satisfecho consigo mismo y de la propia vida.

Componente de adaptación-ajuste (adaptability)

- Este componente se refiere a la capacidad del individuo para evaluar correctamente la realidad y ajustarse de manera eficiente a nuevas situaciones, así como a su capacidad para crear soluciones adecuadas a los problemas diarios. Incluye las nociones de prueba de la realidad (reality testing), flexibilidad (flexibility) y capacidad para solucionar problemas (problem solving).

Fuente: Bar-On et al. (2000).

hace del término capacidades "no cognitivas" en cuanto se relaciona con la inteligencia emocional.

El modelo desarrollado por Bar-On introduce el término cociente emocional (EC), el cual, relacionado con la IE, señala que la esfera emocional y la cognitiva contribuyen en igual medida a las potencialidades de una persona; es decir que esta confluencia explica cómo un individuo se relaciona con las personas que lo rodean y con su ambiente.

Si bien Bar-On, con el objeto de sostener su afirmación, ha conducido estudios que buscan la relación de la IE con la salud física y psicológica, la interacción social, el rendimiento escolar y laboral, bienestar subjetivo y la realización del ser. De esta misma forma el modelo ha encontrado su aplicabilidad en diversos contextos, como el laboral, educativo, médico clínico y de investigación en programas de prevención (Mancini \& Trobini, 2011). Por otro lado, los expertos que han puesto en discusión el modelo de Bar-On se refieren en fuerte medida al interrogante que suscita la etiqueta de la dimensión psicológica, que describe el modelo con el término Inteligencia Emotiva como un conjunto de características personales ligadas a las emociones (D’Amico,2008).

\section{Instrumentos de medición de IE}

La revisión de la literatura que se está llevando a cabo ha permitido notar la existencia de distintos métodos e instrumentos de medición de la IE (ej., Bar-On, 1996; Ciarrochi et al., 2000; Davies et al., 1998; Dawda \& Hart, 2000; Goleman, 1999; Goleman et al., 2002; Mayer, Caruso \& Salovey, 2000b; Mayer \& Salovey, 1997; Mayer et al., 2000a; Schutte et al., 1998; Tapia, 2001; Wong \& Law, 2002). Sin embargo, esto no ha permitido la elaboración de un consenso entre los investigadores acerca de cuál método es el mejor.

Prosiguiendo la revisión acerca de los instrumentos de medición, se han identificado tres tipos de método: 1) test de competencias, 2) cuestionarios de autodescripción, 3) método de los informadores. En los test de competencia el individuo es estimulado a desempeñar diversas tareas, entre las cuales está la resolución de problemas, que presuponen la existencia de una respuesta "correcta" y por lo tanto reveladora de una IE más elevada. Un ejemplo ilustrativo es el Multifactor Emotional Intelligence Scale (MEIS) y su versión mejorada, el MSCEIT (Mayer, Salovey \& Caruso, 2002; Mayer et al., 1999). El problema mayormente relacionado 
con este tipo de test está en la selección de las tareas más pertinentes y la determinación de la respuesta correcta o más ajustada al concepto de IE.

En los cuestionarios de autodescripción, los individuos son invitados a autodescribirse mediante las respuestas a diversas informaciones; ejemplos ilustrativos son el EQ-i desarrollado por Bar-On (1997) y el Trait Meta-Mood Scale (Salovey, 1999); en este sentido, se presume que las personas manifiestan capacidades de autoanálisis y de autoconocimiento. Pero hay razones para suponer que las personas tengan un concepto de sí mismas desajustado. De esta misma forma, en determinados casos, los individuos son confrontados con preguntas potencialmente inductoras de respuestas influenciadas por la deseabilidad social; por tanto, algunas escalas autodescriptivas pueden reflejar el autoconcepto del individuo o su percepción de deseabilidad, pero no su descripción "real"; este tipo de indicador se designa como "índice de inteligencia emocional percibida o autoinformada" y revela las creencias y expectativas de los individuos sobre sus percepciones, discriminaciones y regulación de sus emociones (Extremera \& Berrocal, 2004)

En el método de los informadores se solicita a observadores (ej., colegas de trabajo, superiores jerárquicos, compañeros de curso) posicionar a un sujeto en relación con algunas afirmaciones; esta forma de evaluar los niveles de la IE parte de la preconcepción: si la IE implica la capacidad para manejar y comprender las emociones de las personas que están en nuestro entorno, ¿por qué no preguntarles a las personas más cercanas a nosotros sobre cómo manejamos nuestras emociones en público y la forma de afrontar los sucesos que se nos presentan en nuestra vida cotidiana? (Extremera \& Berrocal, 2004). Este procedimiento permite la valoración de la inteligencia emocional interpersonal vista por un observador externo, pero cercano al sujeto evaluado. En la perspectiva de los expertos, este método produce beneficios al ser una medida complementaria puesto que disminuye el riesgo o sesgo de la deseabilidad social que se presentaba con el método de autoinforme; es por esto que algunos cuestionarios de valoración de la IE implementan instrumentos de observación externa.

\section{EQ-i de Bar-OnTítulo}

La prueba EQ-i tiene por objetivo identificar el grado en el que se presentan los componentes emocionales y sociales en la conducta, optando por la estrategia de medición de autorreporte (Bar-On, 2000) dirigido a sujetos de 17 años; está compuesta por 133 ítems y está dividida en cinco factores generales que se descomponen en un total de 15 subescalas: 1) inteligencia intrapersonal: evalúa las habilidades de autoconciencia-emocional, autoestima personal, asertividad, autoactualización e independencia; 2) inteligencia interpersonal, que comprende las subescalas de empatía, relaciones interpersonales y responsabilidad social; 3) adaptación, que incluye las habilidades de solución de problemas, comprobación de la realidad y flexibilidad; 4) gestión del estrés, compuesta por las subescalas de tolerancia al estrés y control de impulsos, y 5) humor general, integrada por las subescalas de felicidad y optimismo. Además, el inventario incluye cuatro indicadores de validez que miden el grado con que los sujetos responden al azar o distorsionan sus respuestas y cuyo objetivo es reducir el efecto de deseabilidad social e incrementar la seguridad de los resultados obtenidos (Extremera\& Fernández, 2004; D’Amico, 2008).

Los estudios empíricos han demostrado también un nivel de validez y confiabilidad alta con un alfa de Cronbach igual a .93 como lo subrayan Dawda \& Hart (2000), Petrides \& Furnham (2001), en De Caro \& D'Amico (2008). La prueba EQ-i ha sido adaptada y aplicada en diferentes países y culturas. En relación con esto, se consideran los estudios realizados por Bar-On $(1997,2000)$, que se destacan por su minuciosidad, así como por la aplicabilidad del instrumento para muestras con características múltiples (cronológicas, culturales y geográficas). Por estos motivos se acredita al EQ-i la facultad de predecir la IE entre las culturas y su medición de una manera más comprensiva (Matthews et al., 2002). Sin embargo, se han discutido las limitaciones que el autor reporta como estrategia de medición, así como los resultados mixtos respecto a 
los ítems del modelo. Además, los detractores del modelo sugieren que este inventario mide características de personalidad en lugar de la IE (Dawda \& Hart, 2000).

\section{Test MSCEIT: Mayer Salovey-Caruso Emotional Intelligence}

Mayer \& Salovey (1998) empezaron probando la validez de su modelo de las cuatro ramas de la inteligencia emocional con el Multibranch Emotional Intelligence Scale (MEIS), compuesto por 12 subescalas de medida de la inteligencia emocional. La evaluación con el MEIS hace una distinción con la inteligencia clásica con tres subfactores separados: la percepción emocional, la comprensión emocional y la gestión emocional. La MEIS encontró evidencia limitada para la rama de inteligencia emocional relacionada con integrar las emociones; además, con la MEIS se encontró evidencia de validez discriminante en la inteligencia emocional, indicando una independencia de la inteligencia general y la empatía autorreportada, lo que muestra su habilidad para medir las cualidades de un individuo no contempladas en otras pruebas. Una de las limitaciones más significativas del test MEIS era su extensión (402 ítems), al igual que no logró proporcionar evidencia satisfactoria para la integración de las cuatro ramas del modelo de Mayer, Salovey y Caruso. Por esta y otras razones, el grupo de investigadores decidió desarrollar un instrumento nuevo que pudiese medir la inteligencia emotiva.

El instrumento mayormente utilizado para la medición de la inteligencia emocional fue desarrollado por Mayer, Salovey y Caruso, y tiene como nombre Mayer Salovey-Caruso Emotional Intelligence Test $^{1}$ (MSCEIT) ${ }^{2}$. Este test fue normalizado sobre una muestra de 5.000 hombres y mujeres en la versión americana. El MSCEIT se diseñó para ser suministrado a personas de 17 años de edad o más, tiene como objetivo medir las cuatro habilidades descritas en el modelo de Salovey y Mayer de la inteligencia emocional. Cada habilidad (percepción, facilitación del pensamiento, comprensión y regulación) se mide con tareas específicas. La percepción de la emoción se mide por la calificación de la extensión y el tipo de emoción expresada en diferentes tipos de imágenes. La facilitación del pensamiento se mide preguntando al individuo cómo establece paralelismos entre las emociones y las sensaciones físicas (por ejemplo, la luz, el color, la temperatura), así como las emociones y pensamientos. El entendimiento se mide pidiendo al sujeto que explique cómo las emociones pueden mezclarse unas con otras (por ejemplo, la ira y la rabia). La regulación (o gestión) de las emociones se mide por cómo la gente elige una técnica de autorregulación, y no otras.

Con menos de un tercio de los ítems que poseía el MEIS, el MSCEIT incluye 141 ítems. El test proporciona seis puntuaciones: una puntuación global en inteligencia emocional (expresada como un cociente de inteligencia emocional o EIQ), dos anotaciones de área (inteligencia experiencia, o EEIQ, e inteligencia emocional estratégica, SEIQ), y cuatro puntajes correspondientes a las cuatro ramas. Cada puntuación se expresa en términos de una inteligencia estándar con una puntuación media de 100 (puntuación media obtenida) en una población general y una desviación estándar de 15 . Además, el manual proporciona calificaciones cualitativas que corresponden a cada pregunta numérica. Por ejemplo, una persona que recibe un EIQ total de 69 o menos se calificaría en "un desarrollo considerable", mientras que alguien que obtiene 130 o más calificaría como "fuerza importante" (Mayer, Salovey \& Caruso, 2002).

Algunos de los estudios más representativos realizados con el MSCEIT han expuesto la existencia de relaciones significativas entre la IE y el ajuste personal y social (Mayer, Roberts \& Barsade, 2008). En lo concerniente al comportamiento social, se ha podido relacionar que a mayor puntuación IE, con mejor percepción de las competencias sociales

1 La versión italiana del MSCEIT fue realizada por Curci \& D’Amico (2010), en la que la muestra para su estandarización estaba compuesta por 117 sujetos con una edad comprendida entre 17 y 83 años de edad.

2 La versión en español de lMSCEIT fue realizada por Extremera, Fernández \& Salovey (2006), con una muestra de946 estudiantes de enseñanza media y universitaria con un rango de edad de 16 a 58 años. 
y un menor uso de las estrategias personales negativas, como se ha podido constatar en los trabajos realizados por Brackett, Rivers, Shiffman, Lerner \& Salovey (2006), Lopes (2004); en esta misma línea las personas con un nivel alto de IE consiguen tener mejor y mayor calidad en sus relaciones sociales o familiares (Extremera \& FernándezBerrocal, 2004) y de pareja (Brackett et al., 2005). En los estudios que indagan el ajuste personal se ha logrado asociar de forma significativa variables determinantes como la autoestima, el bienestar psicológico, y una correlación negativa con el riesgo social (Brackett \& Mayer, 2003). Por lo que respecta a las personas con un nivel de IE alto, tienden a ser percibidas por sus pares como personas más agradables, empáticas y por demás sociables (Lopes, Salovey, Cote \& Beers, 2005). Los resultados apenas descritos demuestran cómo el manejo apropiado de las emociones juega un papel importante respecto al desarrollo psicosocial. Es por esto que las personas que son reconocidas como emocionalmente inteligentes suelen poseer una buena capacidad en el percibir, comprender y regular sus emociones, lo cual repercute de manera positiva en el bienestar personal. Además, son capaces de transmitir estas habilidades en las emociones en quienes los rodean, mejorando así sus relaciones familiares, sociales e íntimas.
Test IE ACCME (Inteligencia Emocional: Habilidad, Creencias y Concepto de Sí Mismo MetaEmocional (D'Amico, 2013) ${ }^{3}$

El test al cual se hará referencia en las siguientes líneas se publicó recientemente en Italia; se llama test IE ACCME por sus siglas en italiano (Inteligencia Emocional: Habilidad, Creencias y Concepto de Sí Mismo Meta-Emocional).Dicho instrumento fue concebido para la medición de diferentes aspectos de la IE, basándose en la metodología de autorreporte (self report), y en la de habilidades de base (ability based), direccionado a preadolescentes y adolescentes desde 10hasta 18 años.

Según la autora, el test es un instrumento dirigido a la valoración de la inteligencia emocional en preadolescentes y adolescentes; es de carácter primordial al considerar en este rango de edad los cambios sufridos a causa de los procesos de maduración en el plano neurofisiológico, al igual que los cambios generados por las experiencias sea a nivel educativo como de vida; además porque podría ayudar a dar explicaciones más claras acerca de las diferencias adaptativas de los adolescentes y preadolescentes (D’Amico,2013).

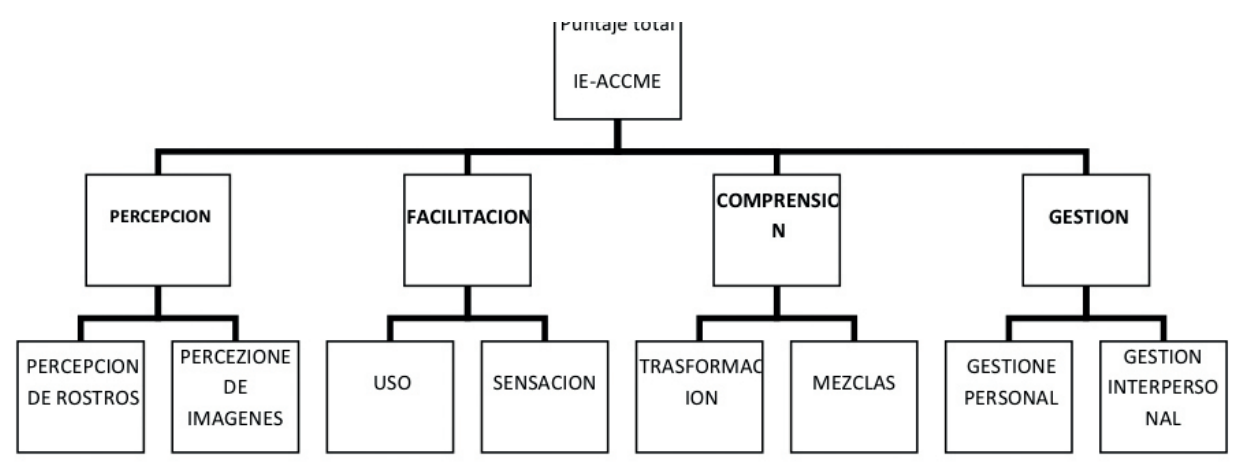

Figura 1. Dimensiones de la inteligencia emocional exploradas en el test IE-ACCME.

La autora logra en definitiva reproducir en gran medida el modelo de las cuatro ramas de la inteligencia emocional de Mayer \& Salovey (1997), en la prospectiva del test de inteligencia emocional de Mayer, Salovey \& Caruso (2002).

Fuente: elaboración propia.

3 Para mayor información véase el Test IE ACCME (D’Amico, 2013) 
La estructura de este instrumento permite la medición de las cuatro ramas de la inteligencia emocional, definidas en el modelo de Mayer \&y Salovey (1997): 1) percepción emocional, 2) asimilación emocional, 3) comprensión emocional y 4) manejo emocional; a través de métodos de medición diferentes. Cada rama de la inteligencia emocional viene explorada como se describe seguidamente:

1. Creencias que el individuo posee sobre las emociones $(\mathrm{CE})$.

2. Concepto de sí mismo meta-emocional, entendiéndose como la autopercepción de las competencias en un determinado dominio de las emociones (CME).

3. Habilidad emocional (AE): se realiza a través de la presentación de una serie de ejercicios que requieren la elaboración de información emocional, expresada en término de grado de consenso entre las respuestas dadas por el sujeto y las obtenidas por la mayoría de los sujetos del grupo de estandarización (consenso general) y de un grupo de expertos estudiosos de las emociones (consenso experto).

4. Autoevaluación de rendimiento (AP) obtenida de la evaluación que cada sujeto realiza sobre su propia performance en el test de habilidad.

- Cuestionario de las creencias que el individuo tiene sobre las emociones: el cuestionario está compuesto por 16 preguntas que exploran las creencias relativas a las ocho dimensiones de las emociones evaluadas en el modelo de Mayer \& Salovey (1997). El objetivo principal de esta escala es el de indagar las creencias de los sujetos en lo que respecta al papel de las emociones en la percepción y sensaciones en la vida cotidiana, en la facilitación de los procesos de pensamiento, y también respecto a la posibilidad de que las emociones puedan ser comprendidas en modo inequívoco y reguladas tanto a nivel personal como interpersonal.

\section{- El cuestionario sobre el concepto de sí mismo} está compuesto por 20 preguntas que exploran la autopercepción de los individuos relacionada con la propia habilidad emocional, en las ocho dimensiones previstas en el modelo de Mayer \& Salovey (1997).

La metodología de respuesta utilizada en este cuestionario es de autorreporte, en el cual se solicita a los individuos atribuirse un puntaje de 0 a 4 acerca de su propia habilidad, para reconocer las emociones en rostros, imágenes y sensaciones, la utilización de las emociones en los procesos de pensamiento, además de comprender el léxico y la transformación de las emociones y el manejo o gestión de los estados emocionales en la esfera personal y en relación con otros.

- Test de habilidad emocional: en esta sección se exploran las habilidades emocionales de los sujetos con la modalidad prevista en los test de ability-based. La autora refiere la similitud que esta tiene con el test MSCEIT (Mayer, Salovey \& Caruso, 2002), ya que es este el modelo inspirador en el cual se basa el IE ACCME en lo que respecta a esta parte del test, que tiene como principal función la de indagar la habilidad objetiva del sujeto en el desempeño de algunos ejercicios (tareas) de tipo emocional.

El test de habilidad emocional del IE-ACCME está compuesto por ocho tareas que exploran la relativa habilidad emotiva del sujeto previstas en el modelo de Mayer \&Salovey (1997), tales como la percepción de las emociones (en rostros, imágenes abstractas y paisajes); la facilitación de las emociones en los procesos cognitivos (uso de sensaciones); la comprensión de las emociones (mezclas y transformación de las emociones); la gestión de situaciones de problem solving emocional (personal e interpersonal).

A pesar de la gran similitud que esta sección del IE ACCME tiene con el MSCEIT, esto no quiere indicar que sea completamente igual, ya que se diferencia sustancialmente en la forma, el contenido de las diversas tareas, el número de preguntas y el sistema algorítmico utilizado para la obtención del puntaje.

Otra de las similitudes que tiene el test de habilidad con el MSCEIT es el método utilizado para establecer el grado de exactitud de las respuestas. 
Así se pueden obtener dos series de puntajes en el test de habilidad del IE-ACCME: es decir, las basadas en el grupo de consenso general y las basadas en el grupo de consenso experto. En el caso del consenso general, las respuestas de los sujetos a las preguntas vienen registradas y a cada una de estas respuestas viene atribuido un puntaje equivalente a la proporción de sujetos de la muestra de estandarización de la población italiana, es decir, el consenso general que ha seleccionado como válida cada alternativa de respuesta. Por ejemplo, una respuesta seleccionada por el $70 \%$ de sujetos de la muestra de estandarización nos diría que cada sujeto que haya elegido esa respuesta obtendrá un puntaje para aquella pregunta igual a .70.La muestra para la estandarización de este instrumento fue constituida por un total de 1.123 sujetos con una edad entre 10 y 19 años.

La atribución del puntaje basado en el consenso experto sigue el mismo procedimiento, con la única diferencia que en este caso se toman en consideración las respuestas dadas por un grupo de estudiosos delas emociones. En particular, este grupo fue constituido por 40 estudiosos italianos, como docentes universitarios, clínicos, doctorandos y especialistas.

- Autoevaluación de rendimiento (AP): la escala de autoevaluación está distribuida a lo largo de todo el test de Habilidad Emocional. En efecto, luego de finalizar cada tarea, viene propuesta una pregunta de autoevaluación acerca del propio rendimiento hacia la propia tarea, con un método de respuesta estilo escala Likert a 6 puntos. La modalidad de valoración fue escogida por la autora a fin de evaluar el grado de conciencia del sujeto acerca de la propia performance en la realización del test, lo cual permite evaluar cuánto se ha sentido más o menos seguro el sujeto con las respuestas dadas en el test.

Por lo que respecta al método de obtención del puntaje, es demasiado complejo, debido a que es casi imposible calcular dichos puntajes manualmente si no se cuenta con los datos obtenidos con la muestra normativa y los algoritmos de cálculo. Por esta razón, para la obtención de los resultados es necesario el envío de las hojas de respuestas compiladas a la editorial Giunti O.S. para el cálculo automatizado y la restitución de los puntajes estandarizados.

Todos los puntajes de los diferentes cuestionarios $\mathrm{CE}, \mathrm{CME}$ y el test de habilidad emocional son convertidos por el programa utilizado para la obtención del puntaje, en puntajes estándar, con una media de 100 y una desviación estándar de 15.

Es posible solicitar a la editorial los puntajes, escogiendo entre el criterio de consenso general y el de consenso experto. En el caso en el que se quiera confrontar los datos del sujeto en examen con categorías aún más detalladas, es posible solicitar los puntajes relacionados según los siguientes subgrupos:

- Consenso general: solo género masculino.

- Consenso general: solo género femenino.

- Consenso general: solo grupo edad escuela superior de primer grado.

- Consenso general: solo grupo edad escuela superior de segundo grado, primer bienio.

- Consenso general: solo grupo edad escuela superior de segundo grado, segundo trienio.

Las potencialidades del test IE ACCME son muchas, pues permite la definición de un perfil de habilidad emocional medida según el criterio de consenso; se puede obtener de igual manera una comparación entre la habilidad y la dimensión metaemocional (autoevaluación y la conciencia), y mide además el grado de discrepancia entre el conocimiento declarado y el comportamiento referido. Al mismo tiempo, el test puede ser utilizado en el ámbito clínico-diagnóstico, al igual que en el contexto educativo, donde puede ayudar a mejorar los niveles de conciencia metaemocional, y la iniciación de procesos o proyectos de reflexión y potenciación de específicas habilidades emocionales. 


\section{Estudios experimentales de IE}

Las investigaciones empíricas sobre la IE han sido muy fértiles en casi todos los aspectos, pero en particular se puede destacar el campo de la educación; los trabajos realizados en este campo van desde las destrezas más elementales, como la identificación de rostros faciales, hasta las de más complejidad, como la regulación emocional en situaciones estresantes. Estas investigaciones se han centrado en la evaluación de las distintas habilidades, por ejemplo percepción de las emociones, identificación de emociones, su relación positiva con la empatía, la emoción como facilitadora del pensamiento, la relación entre la tarea y la emoción, conocimiento emocional y regulación.

De los trabajos que se destacan en las categorías mencionadas líneas atrás, se encuentran los estudios en relación con la percepción de emociones realizados por Mayer, Di Paolo \& Salovey (1990), los cuales lograron identificar estímulos visuales como expresiones faciales, colores y diseños abstractos entre los estudiantes universitarios. En este mismo sentido, se destaca el estudio en relación con identificación de emociones y su vínculo positivo con la empatía. Los resultados obtenidos con este estudio mostraron que, si las personas que respondían los test tenían un estado de ánimo negativo, su percepción se direccionaba hacia el efecto negativo de los estímulos que le eran presentados; en consecuencia, este grupo de investigadores concluyeron que para entender los estados emocionales de las personas que nos rodean se requiere previamente identificar sus emociones. Con relación a los estudios realizados acerca de la emoción como facilitadora del pensamiento, Fernández-Berrocal (1995) pudo comprobar que las tareas de tipo perceptivo, y en cuestionarios como los de razonamiento y la resolución de problemas, los estados de ánimo juegan un papel determinante en la forma en que se nos presenta la información. Por lo que respecta a la investigación delas relaciones entre la tarea $y$ la emoción, Elliz \& Ashbook (1988) y Oaksford, Morris, Grainger, Williams \& Mark (1996) lograron determinar en sus investigaciones que, cuando la tarea a desarrollar es demasiado compleja y la emoción es muy fuerte, se produce un déficit en la ejecución de la tarea. En cuanto a los estudios acerca del conocimiento emocional, Mayer \& Salovey (1995) y Mayer \& Gener (1996) estudiaron la capacidad de identificar emociones desde el discurso; los resultados obtenidos concluyeron que esta destreza proviene de una mayor sensibilidad a las relaciones emocionales internas y externas de cada individuo. Además, se identificó que existe un amplio conocimiento de las conexiones entre pensamiento y emoción.

En un importante estudio Mavroveli \& Petrides (2008)demostraron que la inteligencia emocional rasgo en niños entre 8 y 11 años no está correlacionada con la inteligencia verbal. Estos resultados están en línea con numerosos estudios que han demostrado que la inteligencia emocional rasgo es una medida independiente de IQ. De este estudio se desprende igualmente que la IE rasgo no está correlacionada con el rendimiento académico, a diferencia de los hallazgos de los estudios con personas mayores.

Recientemente, Fernández-Berrocal et al. (2011) examinaron la relación entre la inteligencia emocional, la ansiedad y la depresión en un grupo de adolescentes. El estudio arrojó los siguientes resultados: 1) la regulación del estado de ánimo (reparación emocional) se correlaciona positivamente con la autoestima, 2) la inteligencia emocional se autoevaluó negativamente correlacionada con los niveles de ansiedad y depresión. Estos resultados validan la hipótesis de que las habilidades emocionales son un factor determinante para el ajuste psicológico.

Finalizando con las categorías enunciadas anteriormente, Josephson, Singer \& Salovey (1996) realizaron estudios de laboratorio acerca de la regulación emocional, partiendo del hecho de que algunas personas al experimentar emociones negativas recurren a estrategias para alcanzar estados emocionales de naturaleza positiva. En este estudio se analizó cómo los individuos recuperaban determinados estados "recuerdos" para reparar sus estados emocionales negativos; en otro trabajo sobre esta misma vertiente de investigación (Martínez Ponz, 1997) se hace referencia acerca de cómo la IE se relaciona con la percepción de la calidad de vida, el dominio de tareas y la sintomatología depresiva. 


\begin{tabular}{|c|c|c|c|c|}
\hline $\begin{array}{c}\text { Ámbito de } \\
\text { investigación }\end{array}$ & Fuente & Instrumento & Muestra & Resultados \\
\hline AJUSTE PSICOLÓGICO & $\begin{array}{l}\text { Fernández-Berrocal, } \\
\text { Alcalde \& Ramos (1999) } \\
\text { Ciarrochi, } \\
\text { Chan \& Bajgar } \\
\text { (2001) } \\
\text { Ciarrochi, } \\
\text { Chan \& Caputi } \\
\text { (2000) } \\
\text { Salovey, } \\
\text { Stroud, } \\
\text { Woolery \& Epel } \\
\text { (2002) } \\
\text { Salovey, } \\
\text { Mayer, } \\
\text { Goldman, } \\
\text { Turvey \& Palfai } \\
\text { (1995) } \\
\text { Lopes, } \\
\text { Salovey \& } \\
\text { Straus (2003) } \\
\text { Ciarrochi, Deane \& } \\
\text { Anderson } \\
\text { (2002) }\end{array}$ & $\begin{array}{l}\text { Medida de } \\
\text { autoinforme: Trait } \\
\text { Meta-Mood Scale } \\
\text { (TMMS) } \\
\text { Medida de } \\
\text { autoinforme: } \\
\text { Schutte } \\
\text { Scale } \\
\text { Medida de } \\
\text { habilidad: } \\
\text { MEIS } \\
\text { Medida de } \\
\text { autoinforme: Trait eta- } \\
\text { Mood Scale } \\
\text { (TMMS) } \\
\text { Medida de } \\
\text { autoinforme: Trasxzzz } \\
\text { Medida de } \\
\text { habilidad: } \\
\text { MSCEIT } \\
\text { Medida de } \\
\text { autoinforme: Schutte } \\
\text { Scale }\end{array}$ & $\begin{array}{l}\text { Estudiantes } \\
\text { adolescentes } \\
\text { españoles de } \\
\text { ESO } \\
\text { Estudiantes } \\
\text { adolescentes } \\
\text { australianos } \\
\text { Estudiantes } \\
\text { universitarios } \\
\text { australianos } \\
\text { Estudiantes } \\
\text { universitarios } \\
\text { americanos } \\
\text { Estudiantes } \\
\text { universitarios } \\
\text { americanos } \\
\text { Estudiantes } \\
\text { universitarios } \\
\text { americanos } \\
\text { Estudiantes } \\
\text { universitarios } \\
\text { australianos }\end{array}$ & 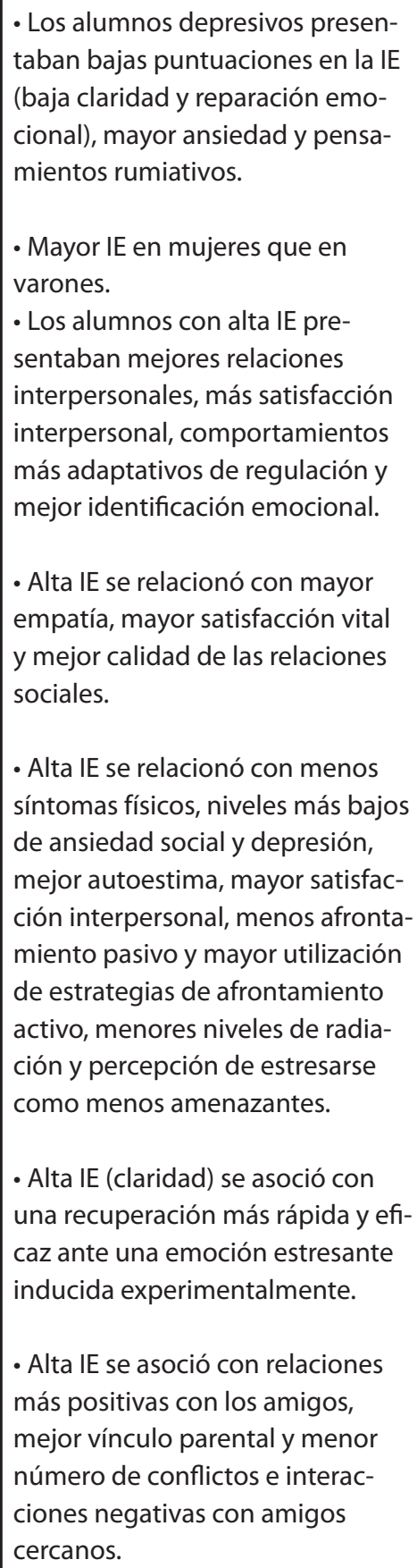 \\
\hline
\end{tabular}

4 Tomado de Orígenes, evolución y modelos de inteligencia emocional (Flores \& Rivas, 2005). 


\begin{tabular}{|c|c|c|c|c|}
\hline $\begin{array}{l}\text { RENDIMIENTO } \\
\text { ESCOLAR }\end{array}$ & $\begin{array}{l}\text { Fernández-Berrocal, } \\
\text { Extremera \& } \\
\text { Ramos } \\
\text { (en revisión) } \\
\text { Shutte, } \\
\text { Malouff, Hall, } \\
\text { Haggerty, } \\
\text { Cooper } \\
\text { \& Barchard } \\
\text { (2000) }\end{array}$ & $\begin{array}{l}\text { Medida de } \\
\text { autoinforme: } \\
\text { Trait-Meta- } \\
\text { Mood Scale } \\
\text { (TMMS) } \\
\text { Medida de } \\
\text { autoinforme: } \\
\text { Schutte } \\
\text { Scale } \\
\text { Medida de } \\
\text { habilidad: } \\
\text { MSCEIT }\end{array}$ & $\begin{array}{l}\text { Estudiantes } \\
\text { adolescentes } \\
\text { de ESO } \\
\text { españoles } \\
\text { Estudiantes } \\
\text { universitarios } \\
\text { australianos }\end{array}$ & $\begin{array}{l}\text { - Alta IE se relacionó con menor } \\
\text { sintomatología ansiosa y depresiva } \\
\text { y menor tendencia a pensamien- } \\
\text { tos intrusivos; justamente los que } \\
\text { presentaron menores síntomas de } \\
\text { depresión obtuvieron mejor rendi- } \\
\text { miento académico. } \\
\text { - Alta IE al principio del curso } \\
\text { académico predecía significativa- } \\
\text { mente la nota media del alumnado } \\
\text { al finalizar el año. } \\
\text { - Controlando habilidades cogniti- } \\
\text { vas y variables de personalidad, los } \\
\text { niveles de IE de los universitarios } \\
\text { predecían las notas obtenidas al } \\
\text { finalizar el año lectivo. }\end{array}$ \\
\hline $\begin{array}{l}\text { CONDUCTAS } \\
\text { DISRUPTIVAS }\end{array}$ & $\begin{array}{l}\text { Rubín (1999) } \\
\text { Extremera \& } \\
\text { Fernández-Berrocal } \\
\text { Trinidad \& } \\
\text { Johnson } \\
\text { (2002) } \\
\text { Brackett \& } \\
\text { Mayer } \\
\text { Maldonado } \\
\text { \& Extremera } \\
\text { (2000) }\end{array}$ & $\begin{array}{l}\text { Medida de } \\
\text { habilidad: } \\
\text { MEIS } \\
\text { Medida de } \\
\text { autoinforme: } \\
\text { Trait Meta- } \\
\text { Mood Scale } \\
\text { (TMMS) } \\
\text { Medida de } \\
\text { habilidad: } \\
\text { MEIS } \\
\text { Medida de } \\
\text { habilidad: } \\
\text { MSCEIT } \\
\text { Medida de } \\
\text { autoinforme: } \\
\text { Trait Meta- } \\
\text { Mood Scale } \\
\text { (TMMS) }\end{array}$ & $\begin{array}{l}\text { Estudiantes } \\
\text { adolescentes } \\
\text { americanos } \\
\text { Estudiantes } \\
\text { adolescentes } \\
\text { españoles de } \\
\text { ESO } \\
\text { Estudiantes } \\
\text { adolescentes } \\
\text { americanos } \\
\text { Estudiantes } \\
\text { universitarios } \\
\text { americanos } \\
\text { Estudiantes } \\
\text { adolescentes } \\
\text { españoles de } \\
\text { ESO }\end{array}$ & $\begin{array}{l}\text { - Alta IE de los alumnos se rela- } \\
\text { cionó con menos comportamien- } \\
\text { tos agresivos en el aula, así como } \\
\text { una mejor valoración del profesor } \\
\text { en conductas prosociales. } \\
\text { - Los alumnos con menor tenden- } \\
\text { cia a justificar comportamientos } \\
\text { agresivos tenían una mayor habili- } \\
\text { dad para poder distinguir sus emo- } \\
\text { ciones (alta claridad emocional), } \\
\text { más capacidad para reparar emo- } \\
\text { ciones negativas y prolongar las } \\
\text { positivas (alta reparación), mayo- } \\
\text { res puntuaciones en salud mental, } \\
\text { niveles más } \\
\text { bajos de impulsividad y una menor } \\
\text { tendencia a la supresión de } \\
\text { pensamientos negativos. } \\
\text { - Alta IE se asoció con menor con- } \\
\text { sumo de tabaco en los últimos } 30 \\
\text { días, menor consumo semanal de } \\
\text { tabaco y menos consumo de alco- } \\
\text { hol en la última semana. } \\
\text { • En varones, alta IE se relacionó } \\
\text { con una mayor tendencia al con- } \\
\text { sumo de drogas ilegales, mayor } \\
\text { consumo de alcohol, mayor } \\
\text { número de peleas y } \\
\text { relaciones negativas con los } \\
\text { amigos. } \\
\text { - Alta IE y mejor ajuste psicológico } \\
\text { se asociaron a menor consumo de } \\
\text { tabaco y alcohol. }\end{array}$ \\
\hline
\end{tabular}

Fuente: Elaboración propia. 
A continuación se evidenciarán en una tabla algunos de los estudios más representativos de la inteligencia emocional en el ámbito educativo.

\section{Resumen y resultados de los estudios en la población inmigrante}

La siguiente revisión de los estudios realizados en la población inmigrante se presentan en este documento, debido a que está en curso una investigación en la cual se desea indagar el impacto de la inteligencia emocional en la adaptación psicosocial de adolescentes y preadolescentes inmigrantes de segunda generación, que frecuentan la escuela en la ciudad de Palermo (Italia).

Una de las investigaciones realizadas con la población inmigrante fue llevada a cabo en España; el objetivo era el de valorar las cinco competencias emocionales según el modelo de Goleman ${ }^{5}$; el estudio tiene como título The emotional competences of autochthonous and immigrant students at the secondary education level (Soriano \& Osorio, 2008); participaron 588 jóvenes entre 13 y 17 años, de los cuales 264 eran hombres y 324 mujeres, 390 eran de nacionalidad española y 198 eran hijos de inmigrantes; fueron agrupados de la siguiente manera: América Latina, países magrebíes, Europa del Este y países subsaharianos); el instrumento utilizado para la recolección de la información fue elaborado por las propias investigadoras, quienes realizaron a la vez un análisis del constructor y la fiabilidad del mismo, el cual dio una puntuación del coeficiente alfa de Cronbach de 0,8316.

Con relación al análisis realizado a las puntuaciones mínimas y máximas obtenidas por grupo cultural de origen, las investigadoras lograron identificar diferencias significativas en el alumnado según las competencias emocionales evaluadas; el alumnado latinoamericano obtuvo la puntuación media superior en las competencias conciencia de uno mismo, motivación y empatía. La mayor puntuación media en autorregulación la obtuvieron los magrebíes, y la media más alta en habilidades sociales, los europeos del Este. Por lo que respecta al análisis según géneros e ha puesto de manifiesto que se establecen diferencias entre mujeres y hombres en las competencias emocionales de autoconciencia y empatía, resultando ambas significativas al 0,000 . Por lo que se puede subrayar que las mujeres muestran más autoestima que los hombres que conocen sus propias emociones y manifiestan más habilidad para entender las necesidades, sentimientos y problemas de los demás (Soriano y Osorio, 2008).

Las investigadoras apuntan que los resultados obtenidos con este estudio son de suma importancia, debido a que contribuye al reconocimiento de las

5 1. Conciencia de uno mismo o autoconciencia. Se refiere a la capacidad de darnos cuenta de manera consciente de nuestras emociones y sentimientos en el mismo momento en que se producen, es decir, es el conocimiento de las propias emociones. Esta competencia incluye aspectos tales como la conciencia emocional, una valoración adecuada de sí mismo y la confianza en uno mismo.

2. Autorregulación. Se entiende como la capacidad para controlar y manejar nuestros sentimientos y emociones propias y los impulsos y recursos de los que disponemos. Las competencias emocionales que dependen de esta son autocontrol, confiabilidad, integridad, adaptabilidad e innovación.

3. Motivación. Es la competencia que propicia que un sujeto sea capaz de conseguir los objetivos propuestos y hacer frente, de una manera óptima y sacándoles el máximo rendimiento a sus potencialidades, a las situaciones de la vida cotidiana. Los aspectos incluidos en esta competencia son la motivación de logro, el compromiso, la iniciativa y el optimismo.

4. Empatía. Es la capacidad de reconocer y percibir las emociones, sentimientos, preocupaciones, necesidades o deseos de los otros. Brevemente, podemos decir que la empatía se refiere a la capacidad que tiene una persona para ponerse en el lugar del otro, para entender sus puntos de vista. Las competencias que dependen de esta son la comprensión de los otros, el desarrollo de los demás, la orientación hacia el servicio, el aprovechamiento de la diversidad y la conciencia política.

5. Habilidades sociales. Se refieren a la capacidad que tiene un individuo para conseguir, por diversos medios, que los demás respondan según se espera en las diversas situaciones. Los aspectos incluidos en esta competencia son la influencia, comunicación, resolución de los conflictos, liderazgo, catalización del cambio, establecer vínculos, colaboración, cooperación y habilidades de equipo. 
competencias emocionales en los jóvenes independientemente de su procedencia geográfica y cultural; permite conocer en qué coinciden y en qué hoy trabajar en todos los aspectos emocionalmente positivos distintivos de cada grupo estudiado, con el fin de facilitar el intercambio, la enseñanza y el aprendizaje, para que todo el alumnado mejore (Soriano y Osorio, 2008).

Otro de los estudios revisados está directamente relacionado con la inteligencia emocional y los estilos de aculturación, la experiencia de aculturación y el ajuste psicológico de los inmigrantes; en el estudio participaron inmigrantes que vivían en Alemania al menos desde hace 15 años; la muestra estaba constituida por 349 (grupo1) participantes de Turquía (102 hombres y 95 mujeres) con una media de 22,8 años, Norte de África (Túnez, Argelia y Marruecos,63 hombres y87 mujeres) con una media de 23,4 años; un segundo grupo con 65(grupo2) participantes que estaban compuestos por turcos y norafricanos (40 hombres y 25 mujeres) con una media de 21,3 años. En este estudio el investigador utilizó los siguientes instrumentos para la obtención de información de los participantes: Trait-Meta-Mood Scale (TMMS), Acculturation Attitudes Scale (AAS), Satisfaction with Life Scale (SWLS), The Subjective Happiness Scale (SHS), and The Beck Depression Inventory (BDI). A continuación se hará mención de los hallazgos encontrados por Schmitz (2012).

El aporte del estudio realizado por Schmitz hace referencia a cómo la inteligencia emocional está directamente relacionada con la preferencia por los estilos de aculturación, en particular con la integración cultural; según Schmitz, con relación a sus hallazgos respecto delos individuos que participaron en el estudio, se identificó que algunos poseían una mayor capacidad analítica para la comprensión de sus propios procesos emocionales y la de los demás; estos sujetos estarían mejor preparados para interactuar con otras personas de una manera socialmente competente. Considera que esta habilidad para regular las emociones es de un valor vital para afrontar con éxito el estrés causado por las expectativas contradictorias que se presentan en los grupos con características culturales diferentes; en este sentido, las habilidades para regular las emociones se convierten en un requisito para mantener relaciones con los diferentes grupos culturales, incluidas la cultura de origen y la del país receptor.

El estudio conducido por Schmitz correlacionó el componente de Separación de la prueba AAS con todos los componentes de la IE que contienen el TMMS; en el análisis de las correlaciones el investigador encontró que había una correlación positiva con el componente de Atención y correlaciones negativas en los componentes del TMMS Claridad y Reparación, lo cual sugiere que los participantes con un alto grado de sensibilidad emocional prefieren evitar el conflicto cultural y escogen mantener las relaciones íntimas solo dentro del propio grupo cultural. Si los sujetos inmigrantes mantuvieran este comportamiento habría menos probabilidades de tener un conflicto cultural. Adicionalmente, Schmitz sugiere que los inmigrantes con una preferencia fuerte por el estilo de aculturación de la Separación tendrían menos Claridad sobre sus emociones y menos capacidad de regularlas. En este mismo orden, los individuos que prefieren como estilo de aculturación la Marginación se caracterizan por tener puntaje bajo en el componente de Claridad y particularmente la Reparación baja; con lo cual se deduce que los inmigrantes que obtienen alta puntuación en inteligencia emocional tienen una menor preferencia por este estilo de aculturación.

Por lo que respecta a las variables de Well Being con el TMMS-24 se logró identificar que los inmigrantes que puntuaban niveles altos de IE tenían una percepción menor frente a la discriminación y los sentimientos de injusticia experimentada; esto puede ser debido a las diferencias individuales en cuanto a la sensibilidad hacia el rechazo, así como la habilidad para regular los efectos negativos de las interacciones interpersonales (Schmitz, 2012).

\section{Conclusiones}

La inteligencia emocional se ha configurado como el resultado del desarrollo, evolución y la combinación de los conceptos de emoción e inteligencia. 
En este orden, se ha considerado la emoción como una habilidad soft o impalpable del ser humano o como una respuesta elaborada a cualquier evento psicológico y cognitivo. Es así como la inteligencia ha sido considerada una habilidad cognitiva clásica de carácter poderoso que podía ser medida en el ámbito psicológico (Stemberg,1985). La evolución y el desarrollo de ambos conceptos han tenido un sinnúmero de propuestas y perspectivas, las cuales incluyen en su interior la influencia que representa el contexto ambiental, las situaciones culturales y personales.

En esta revisión se ha podido evidenciar cómo ha evolucionado el concepto de inteligencia emocional, lo cual ha generado el reconocimiento de los aspectos psicológicos que han sido considerados no cognitivos y que por demás intervienen en el comportamiento humano. En esta perspectiva, los estudios realizados han podido demostrar una correlación significativa entre los aspectos cognitivos y la emoción de las personas, y cómo dicha relación es de carácter predominante para conseguir adecuada comprensión en los diferentes ámbitos de la actividad humana.

La revisión de las bases teóricas de la IE se han ido consolidando poco a poco en el ámbito psicológico, a pesar del desacuerdo marcado respecto a la delimitación de los constructos, lo que a su vez ha tenido como consecuencia los caminos diferentes en el proceso de conceptualización, medición y aplicación que han tomado los principales investigadores que han contribuido al desarrollo del concepto de inteligencia emocional. Si se analiza detenidamente la evolución y desarrollo de la IE, se podría indicar que esta ha culminado la primera fase de teorización, teniendo en consideración que aún se dan algunas discusiones y cuestionamientos acerca de las posiciones teóricas. Lo cual da a entender que el ambiente de crecimiento es bueno; un signo evidente de tal crecimiento es la consolidación de los constructos para la medición de la IE, ya que cada uno en su común denominador busca expresar la dinámica emocional de los individuos en sus ambientes cotidianos, al igual que las consecuencias que dichas dinámicas emocionales tienen en la salud física y mental.
Por lo que respecta al análisis de los instrumento de medición presentados en el presente documento, se debe indicar que en su gran mayoría han sido diseñados para la valoración y medición de la IE en la población adulta, a excepción del test IE ACCME recientemente publicado en Italia, el cual busca llenar un vacío en lo que concierne a los test para la medición de la IE en adolescentes y preadolescentes, que tuvieran como fundamento teórico el modelo de IE propuesto por Mayer \& Salovey(1997).

En este mismo orden, los estudios anteriormente analizados demuestran la necesidad de incorporar a los procesos de aprendizaje las dimensiones de la inteligencia emocional; de hecho, algunos de los aspectos más determinantes en el proceso de aprendizaje no son exclusivamente la adquisición de conocimientos, la capacidad intelectual, sino también la conciencia y la capacidad que cada sujeto tiene para gestionar y controlar sus propias emociones y sentimientos, además de las motivaciones con las cuales enfrenta los procesos de formación y la diversidad de las relaciones interpersonales que establece con los demás.

En la actualidad, se debe reconocer que la escuela y la sociedad se caracterizan como ambientes multiculturales, en los cuales convergen diversas culturas. Algunos estudios realizados en adultos inmigrantes han evidenciado una mayor incidencia de problemas comportamentales y emocionales debido a una pobre capacidad de adaptación a la inmigración (Bagley, 1972; Gaertener-Harnach, 1981; Rutter et al., 1974). En el caso de inmigrantes de segunda generación se presentan algunos problemas, como el retraso de la integración escolar, malestar individual, familiar y una tendencia hacia la desviación social.

El actual contexto multicultural plantea nuevos retos por resolver, por ejemplo los conflictos que surgen en la escuela y en miembros de la familia. Una extensa literatura ha demostrado que la inteligencia emocional (Salovey \& Mayer, 1990, Mayer \& Salovey, 1997) puede ayudar a mejorar las habilidades de las personas en la vida cotidiana. En particular en el sector de la educación, se ha visto cómo la capacidad de percepción, comprensión y 
regulación emocional es vital para la adaptación a nuestro ambiente y contribuir sustancialmente al bienestar psicológico y el crecimiento personal, independientemente del nivel de performance cognitivo o académico de los estudiantes. Es por esto que el autor del presente artículo se encuentra en la fase inicial de investigación en la que se indagará el impacto de la IE en la adaptación psicosocial de adolescentes y preadolescente inmigrantes de segunda generación en la ciudad de Palermo(Italia).

\section{Referencias}

Bar-On, R. (1997a). The Bar-On Emotional Quotient Inventory (EQ-i): A test of emotional intelligence. Toronto: Multi-Health Systems Inc.

Bar-On, R. (1997b). The Bar-On Emotional Quotient Inventory (EQ-i): Technical manual. Toronto: Multi-Health Systems Inc.

Bar-On, R. (2000). Emotional and social intelligence: Insights from the Emotional Quotient Inventory (EQ-i). In: R. Bar-On\& A. Parker (eds.), Handbook of emotional intelligence (pp. 363-388). San Francisco, CA: Josey-Bass.

Brackett, M. A. \& Mayer, J. D. (2003). Convergent, discriminant, and incremental validity of competing measures of emotional intelligence. Personality and Social Psychology Bulletin, 9, 1147-1158.

Brackett, M. A. \& Salovey, P. (2004). Measuring emotional intelligence with the Mayer-Salovey-Caruso Emotional Intelligence Test (MSCEIT). In: G. Geher (ed.), Measuring emotional intelligence (pp. 181-196). New York: Nova Science Publishers.

Brackett, M. A., Warner, R. M., \& Bosco, J. S. (2005). Emotional intelligence and relationship quality among couples. Personal Relationships, 12, 197-212.

Binet, A. (1905). Nouvelles recherchés sur la mesure $\mathrm{du}$ niveau intelletuel chez les enfants d'école. Année Psichologiche, 27, 10-201.
Boyatzis, R. E., Goleman, D., \& Rhee, K. (2000). Clustering competence in emotional intelligence: Insight from the emotional competence inventory. In: R. Bar-On \& J. D. A. Parker (eds.), the handbook of emotional intelligence: Theory, development assessment and application at home, school and in workplace, pp. 343362.San Francisco, CA: Jossey-Bass.

Charbonneau, D. \& Nicol A. A. M. (2002). Emotional intelligence and leadership in adolescents. Personality and Individual Differences, 33, pp.1101-1113.

Ciarrochi, J.V., Chan, A.Y.C., \&Bajgar, J. (2001). Measuring emotional intelligence in adolescents. Personality and Individual Differences, 31, pp. 1105-1119.

Ciarrochi, J.V., Chan, A.Y.C., \&Caputi, P. (2000). A critical evaluation of the emotional intelligence construct. Personality and Individual Differences, 28, 539-561.

Curci, A. \& D’Amico, A. (2010). MSCEIT - MayerSalovey-Caruso Emotional Intelligence Test. Validazione e taratura italiana. Firenze: Giunti Organizzazioni Speciali.

D’Amico, A. \& Curci, A. (a cura di) (2010). MSCEIT - Mayer-Salovey-Caruso Emotional Intelligence Test. Manuale. Firenze: Giunti Organizzazioni Speciali.

D’Amico, A. (2012). Test IE ACCME- Intelligenza emotiva: Abilita, Credenze e Concetto di Sé Meta-Emotivo.Test pre Adolescenti. Firenze: Giunti Organizzazioni Speciali.

De Caro, T. \& D’Amico, A. (2008). L'intelligenza emotiva: Rassegna dei principali modelli teorici, degli strumenti di valutazione e dei primi risultati di ricerca. Giornale Italiano di Psicologia, 4, 853-878.

Davies, M., Stankov, L., \&Roberts, R.D. (1998). Emotional intelligence: In search of an elusive construct. Journal of Personality and Social Psychology, 75, 989-1015. 
Dawda, D. \& Hart, S.D. (2000). Assessing emotional intelligence: Reliability and validity of the Bar-On Emotional Quotient Inventory (EQ-i) in university students. Personality and Individual Differences, 28, pp. 797-812.

Elliz, H. C. \& Ashbook. (1988). Resources allocation model of the effects of depressed mood states on memory. In: Forgas \& Fiedler (eds.), Affect, cognition, and social behavior. Toronto: Nogrefe.

Extremera, N., Fernández-Berrocal, P., \& Salovey, P. (2006). Spanish version of the MayerSalovey-Caruso Emotional Intelligence Test (MSCEIT) version 2.0: reliabilities, age and gender differences. Psicothema,18, pp. 42-48.

Extremera, N. \& Fernández-Berrocal, P. (2004). El papel de la inteligencia emocional en el alumnado: evidencias empíricas. Revista Electrónica de Investigación Educativa,6(2).

Fernández-Berrocal, P. (1995). Cognición social. En: L. Gómez \& J. Canto (eds.),Psicología social. Madrid: Pirámide.

Fernández-Berrocal, P., Alcaide, R., \& Ramos, N. (1999). The influence of emotional intelligence on the emotional adjustment in high school students. Bulletin of Kharkov State University, 439(1-2), pp. 119-123.

Gardner, H. (1983). Frames of mind: The theory of multiple intelligence (10th anniversary ed.). New York: Basic Books.

Galton, F.(1885).On the anthropometric laboratory at the late international health exhibition. Journal of Anthropological Institute, 14, 205-219.

Guilford, J. P. \& Hoepfner, R. (1971). The analysis of intelligence. New York: McGraw-Hill.

Goleman, D. (1995). Emotional intelligence. New York: Bantam Books. Traducción italiana: Intelligenza Emotiva. Milano: Rizzoli, 1996.
Goleman, D. (2001). Emotional intelligence: Issues in paradigm building. In: C. Chernis \& D. Goleman (eds.), The emotional intelligence workplace. San Francisco: Jossey-Bass.

Goleman, D., Boyatzis, R.E., \&McKee, A. (2002). Primal leadership: Realizing the power of emotional intelligence. Boston, MA: Harvard Business School Press.

Josephson, B., Singer, J., \& Salovey, P. (1996). Mood regulation and memory. Repairing sad moods with happy memories. Cognition

Lopes, P. N., Salovey, P., Coté, S., \& Beers, M. (2005). Emotion regulation abilities and the quality of social interaction. Emotion, 5, pp. 113-118.

Mancini,G.\&Trombini, E. (2011). Dalle emozioni all'intelligenza emotive "comprendere per educare”. Torino: Esspres edizioni.

Martínez-Ponz, M. (1997). The relation of emotional intelligence with selected areas of persons functioning. Imagination, Cognition and Personality, 17, pp. 3-13.

Matthews, G., Zeidner, M., \& Roberts, R.D. (2002). Emotional intelligence: Science and myth. Cambridge, MA: MIT Press.

Mavroveli, S., Petrides, K. V., Shove, C., \& Whitehead, A. (2008). Investigation of the construct of trait emotional intelligence in children. European Child an Adolescent Psychiatry, 17, pp. 516-526.

Mayer, J.D., Di Paolo, M.T., \&Salovey, P. (1990). Perceiving affective content in ambiguous visual stimuli: A component of emotional intelligence. Journal of Personality Assessment, 54, pp. 772-781.

Mayer, J.D., Salovey, P., \&Caruso, D. (2002). Mayer-Salovey-Caruso Emotional Intelligence Test (MSCEIT) Item Booklet. Toronto, Ontario: Multi-Health System. 
Mayer, J.D. \& Salovey, P. (1995). Emotional intelligence and the construction and regulation of feelings. Applied and Preventive Psychology, 4(3), pp. 197-208.

Mayer, J. D. \& Geher, G. (1996). Emotional intelligence and the identification of emotion. Intelligence, 22, pp. 89-113.

Mayer, J. D. \& Salovey, P. (1997). What is emotional intelligence? In: P. Salovey \& D. Sluyter (eds.), Emotional development and emotional intelligence: Implications for educators (pp. 3-31). New York: Basic Books.

Mayer, J. D., Caruso D. R. \& Salovey, P. (1998). Multifactor Emotional Intelligence Test (MEIS). Available from John D. Mayer, Department of Psychology, University of New Hampshire.

Mayer, J.D., Caruso, D.R., \&Salovey, P. (1999). Emotional intelligence meets traditional standards for an intelligence. Intelligence, 27(4), pp. 278-298.

Mayer, J.D., Salovey, P., \&Caruso, D. (2000). Models of emotional intelligence. In: R. J. Sternberg (ed.), Handbook of human intelligence, pp. 396-420. New York: Cambridge University Press.

Mayer, J.D., Caruso, D.R., \&Salovey, P. (2000). Selecting a measure of emotional intelligence: The case for ability scales. In: R. Bar-On\& J.D.A. Parker (eds.), Handbook of emotional intelligence (pp. 320-342). San Francisco, CA: Jossey-Bass.

Neubauer, A. \& Freudenthaler, H. (2005). Models of emotional intelligence. In: Schulze \&. Robert (eds.), Emotional intelligence. An international handbook, pp. 31-50. Germany.
Oaksford, M., Morris, F., Grainger, B., Williams, J., \& Mark, G. (1996). Mood, reasoning, and central executive processes. Journal of Experimental Psychology: Learning, Memory and Cognition, 22(2), pp. 476-492.

Salguero, J. M., Fernández-Berrocal, P., Aranda, D., Castillo, R. \& Palomera, R. (2011). Inteligencia emocional y ajuste psicosocial en la adolescencia: el papel de la percepción emocional. European Journal of Education and Psychology, 4, pp. 143-152.

Soriano, E. \& Osorio, M. (2008). The emotional competences of autochthonous and immigrant students at the secondary education level. Bordon, 60(1), pp. 129-148.

Schmitz, P. G. \& Schmitz, F. (2012). Emotional intelligence and acculturation. Behavioral Psychology, 20(1), pp. 15-41.

Stemberg, R. J. (1985). Beyond I. Q.: A Triarchic Teory of Human Intelligence. Cambridge: Cambridge University Press. Traducción italiana: Teorie dell'intellegenza. Milano: Bompiani, 1987.

Tapia, M. (2001). Measuring emotional intelligence. Psychological Reports, 88, pp. 353-364.

Trujillo, M., Arturo, R. \& Tovar, L. Orígenes, evolución y modelos de inteligencia emocional. Innovar, 15(25), pp. 9-24.

Thrustone, L. L. (1938). Primary mental abilities. Psychometric Monograph, 1.Chicago: University of Chicago Press.

Wong, C. S. \& Law, K. S. (2002). The effects of leader and follower emotional intelligence on performance an attitude: An exploratory study. The Leadership Quarterly, 13, 243-274. 